\title{
Landscape Evaluation of Municipalities in Ciezkowice-Roznow Regional Park in Poland
}

\author{
Beata Fornal-Pieniak and Maciej Żołnierczuk \\ Department of Environmental Protection, Warsaw University of Life Science, Warsaw 02-787, Poland
}

\begin{abstract}
The aim of the study was landscape evaluation of municipalities located in Ciezkowice-Roznow regional park in the southern part of Poland. The methodology includes field and indoor studies. Plant communities, natural 2,000 habitats, protected areas, and cultural elements have been identified. The study area has been divided into study units/plots. The next stage of research was the evaluation of landscape elements on every study unit. It distinguished areas with very high, high and moderate landscape values. Directions for shaping the landscape were formulated in the final part of the study.
\end{abstract}

Key words: Landscape evaluation, municipality, Ciezkowice-Roznow regional park.

\section{Introduction}

Landscape may be assessed in a variety of ways through the use of appropriate criteria of assessment and by evaluating them. Evaluation enables the designation of such areas as those of a variety of natural, cultural, or visual values. There is currently no infallible method of evaluating landscape that would provide an objective method of assessing the values of a given area [1]. The goals of evaluation include among others: designating areas under legal protection (i.e. national parks, nature reserves, or landscape parks) and monitoring the state of fauna, etc. on the existing areas and preventing negative anthropogenic impact. Results of evaluation make it possible to draft appropriate recommendations for landscaping including protective activities, or development for tourism.

Literature of the topic presents multiple methods of landscape evaluation including that of Myga-Piątek [2], Żarska [3], SBE, Wehchert's sense curve, Bogdanowski's method of architecture-and-landscape interiors and units, Wojciechowski's method, Janicki's straight lines method and WNET method.

Corresponding author: Beata Fornal-Pieniak, main research fields: landscape planning, vegetation and landscape architecture.
The aim of this work is to assess (evaluate) the landscape of the municipalities on the grounds of the Ciezkowice-Roznow regional park.

Results of the evaluation constitute the basis of data towards the drafting and updating of rational spatial development of the area of the Ciezkowice-Roznow regional park according to the principles of balanced development.

\section{Material and Methods}

Ciezkowice-Roznow regional park is a large legally protected area in the south of Poland. It incorporates the rural communes of Gromnik, Ciężkowice, Rzepiennik Strzyżewski, Zakliczyn (district of Tarnów) and the village of Piaski Drużków in the Czchów commune (district of Brześć). The park, with the area of 176.34 square kilometres, was founded in 1995. There are 121 landscape parks in Poland, totalling $8.5 \%$ of the country's territory (Fig. 1).

According to Kondracki's division [4], the area under study is a part of Pogórze Środkowobeskidzkie (the area of the outlying western Carpathians). Pogórze Środkowobeskidzkie is a hill range mountainous valleys with heights between 300 m.a.s.l. and 500 m.a.s.l. and width of several dozen kilometres. The area under study is dominated by agricultural areas: 


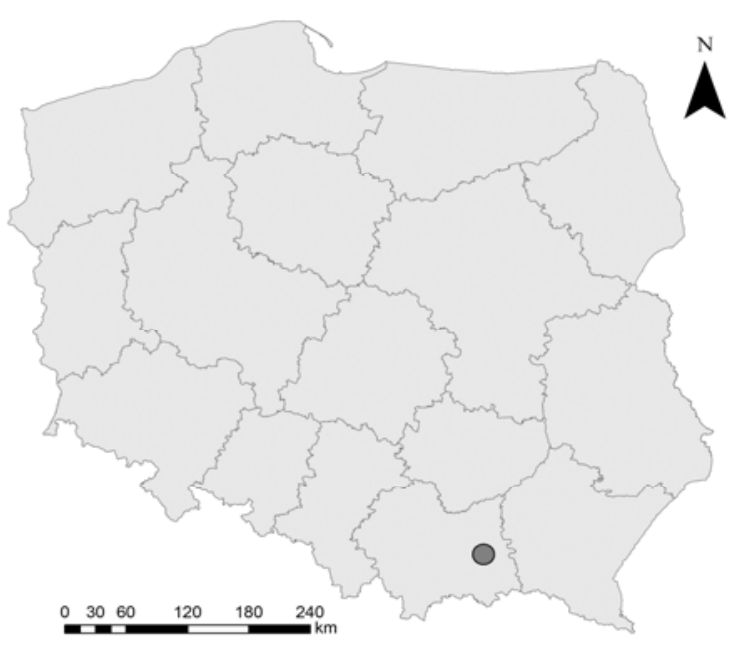

Fig. 1 Localization of study area.

$55 \%$ of park area, $39 \%$ of forests and $6 \%$ of remaining forms of land development. Evaluation criteria were formulated according to the method of Żarska [3], and the evaluation was performed using the point bonitation with a range of 0 to 3 points. The area under study has been divided into 9 study units along the main municipal roads. This method is not regarded well by researchers including landscape architects, planners, and geographers. In spite of this, this criterion of division was applied upon the request of the local authorities. This work mostly assesses the existing flora and cultural environment of the Ciezkowice-Roznow regional park. In order to evaluate the landscape, a modified method of Żarska [3] was used. The main criteria for assessment used are: size of forested area, diversification of plant communities, presence of areas placed under protection, presence of natural monuments, presence of inanimate nature objects, presence of surface waters, presence of lookout points, diversification of cultural elements, presence of harmonious and disharmonious cultural elements (Table 1). Plant communities were identified according to the Matuszkiewicz guide [5].

Based on the evaluation, the areas (study units) with a variety of natural and cultural values have been

Table 1 Assessment criteria and point bonitation used for evaluation of landscape of the area under study.

\begin{tabular}{|c|c|c|}
\hline Main assessment criteria & Detailed criteria & \begin{tabular}{|l} 
Point \\
bonitation
\end{tabular} \\
\hline \multirow{3}{*}{ Size of forested area } & Forested area over $75 \%$ of study unit & 3 \\
\hline & Forested area covering $50 \%$ to $75 \%$ of study unit & 2 \\
\hline & Forested area under $50 \%$ of study unit & 1 \\
\hline \multirow{3}{*}{$\begin{array}{l}\text { Diversification of plant } \\
\text { communities }\end{array}$} & High diversification of plant communities (more than 10 types of plant communities) & 3 \\
\hline & Medium diversification of plant communities ( 5 types to 9 types of plant communities) & 2 \\
\hline & Low diversification of plant communities (less than 5 types of plant communities) & 1 \\
\hline \multirow{3}{*}{ Degree of natural flora } & Dominant natural plant communities (more than $50 \%$ of the area of study unit) & 3 \\
\hline & $\begin{array}{l}\text { Mixture of plant communities (around } 50 \% \text { of natural plant communities and around } \\
50 \% \text { of semi-natural plant communities with a limited share of synanthropic flora) }\end{array}$ & 2 \\
\hline & $\begin{array}{l}\text { Dominant semi-natural or synanthropic plant communities with a limited share of } \\
\text { natural flora) }\end{array}$ & 1 \\
\hline \multirow{3}{*}{$\begin{array}{l}\text { Presence of areas under } \\
\text { protection (other than landscape } \\
\text { park as this is present in all } \\
\text { communes under study) }\end{array}$} & Large areas i.e. national park, natural 2,000 areas, nature reserves & 3 \\
\hline & Smaller protected areas i.e. ecological cultivation & 2 \\
\hline & Isolated protected objects i.e. natural monuments, sites of special importance & 1 \\
\hline \multirow{3}{*}{ Presence of surface waters } & $\begin{array}{l}\text { Diversification of natural surface waters (e.g. rivers, lakes) with a significant presence } \\
\text { of water and water-edge plants }\end{array}$ & 3 \\
\hline & Presence of bodies of water, and natural and artificial flows & 2 \\
\hline & Dominant artificial bodies of water (e.g. ponds and lakes) & 1 \\
\hline \multirow{3}{*}{$\begin{array}{l}\text { Diversification of cultural } \\
\text { elements }\end{array}$} & $\begin{array}{l}\text { Presence of valuable elements of secular and religious culture with dominated by } \\
\text { historic monuments }\end{array}$ & 3 \\
\hline & Presence of valuable secular or sacred sites ( 2 or more) & 2 \\
\hline & Presence of isolated valuable secular or sacred sites & 1 \\
\hline \multirow{3}{*}{$\begin{array}{l}\text { Presence of harmonious and } \\
\text { disharmonious cultural elements } \\
\text { within landscape }\end{array}$} & Dominant harmonious elements within landscape & 3 \\
\hline & Mixture of harmonious and disharmonious cultural elements within landscape & 2 \\
\hline & Dominant disharmonious elements within landscape & 1 \\
\hline
\end{tabular}


designated: areas of very high landscape value 17 points to 21 points, areas of high landscape value 11 points to 16 points, areas of moderate landscape value 5 points to 10 points, and area of low value below 5 points. The final stage of the research was to formulate the conclusions.

\section{Results of the Research and Discussion}

Ciezkowice-Roznow regional park has been divided into 9 study units (Fig. 2). Natural, semi-natural, and synanthropic plant communities have been identified in the area under study. Following forested areas have been identified: Dentario glandulosae-fagetum, Luzulo luzuloides-fagetum, Galio rotundifolii-abietetum, Tilio-Carpinetum, Leucobryo-Pinetum, Querco roboris-pinetum, Abieti-Piceetum, Carici remotae-fraxinetum and Alnetum incanae., riparian forests, water, and water-edge vegetation have mostly developed along the Biała river and smaller flows (Fig. 3). Apart from natural, there are also grassland plants, mostly represented by fresh grasslands (Arrhenatheretum elatioris) and humid grasslands (Molinietum caeruleae and Filipendulo-Geranietum). From xerothermic plants, Thalictro-Salvietum pratensis has been identified. Riparian forests and humid grasslands along with water and water-edge vegetation are growing along the Biała river and smaller streams in the area under study. Synanthropic vegetation is mostly represented by the Artemisietea class commonplace in villages and small towns. Moreover, Echinochloo-Setarietum and Vicietum tetraspermae are communities commonplace in the cultivated parts of the area under study.

Natural 2,000 habitats such as Tilio Carpinetum, Arrhenatheretum elatioris, Thalictro-Salvietum pratensis have also been identified. Forests and agricultural areas were dominated in the area under study. On the grounds of Ciezkowice-Roznow regional park, there are also other forms of nature preservation. These include nature reserves, natural 2,000 areas, sites of special importance and natural monuments. "Skamieniałe Miasto" (fossilized city) is a reserve of inanimate nature, set near Ciężkowice in the eastern part of the area under study (Fig. 4). Sandstone formations shaped by erosion are a characteristic element of its area. The rocks take on a variety of shapes: a badger, eagle or a pyramid. A specific type of protection is mostly devoted to natural monuments such as a standalone tree or a patch of trees. Sites of special importance and ecological cultivation areas have also been designated.

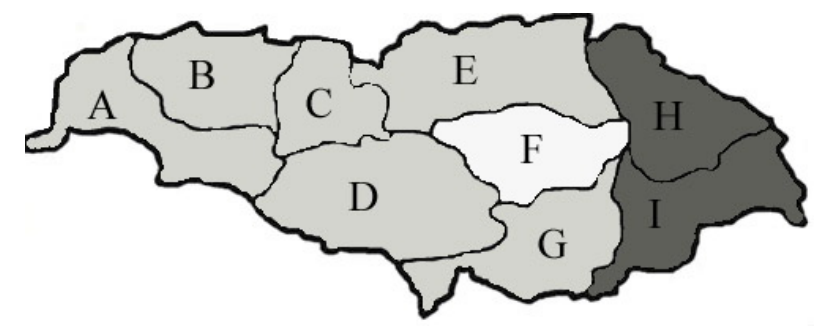

Fig. 2 Results of landscape evaluation of municipalities in Ciezkowice-Roznow regional park in Poland.

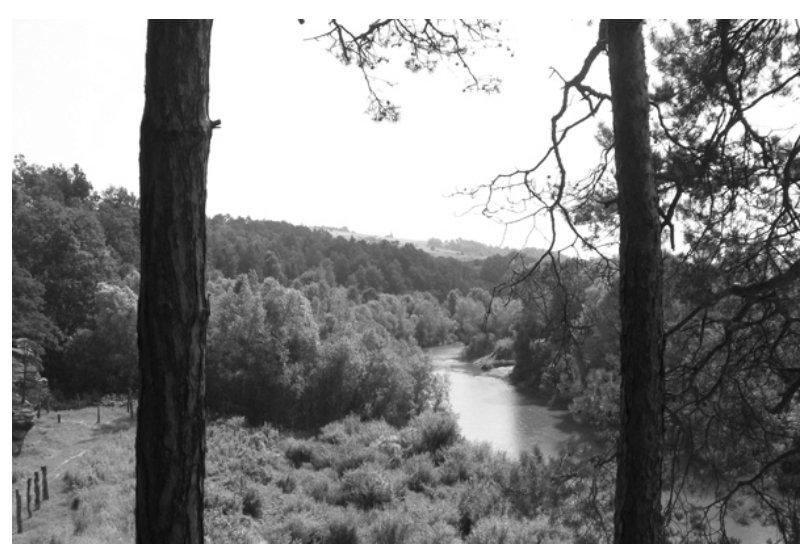

Fig. 3 Biala river.

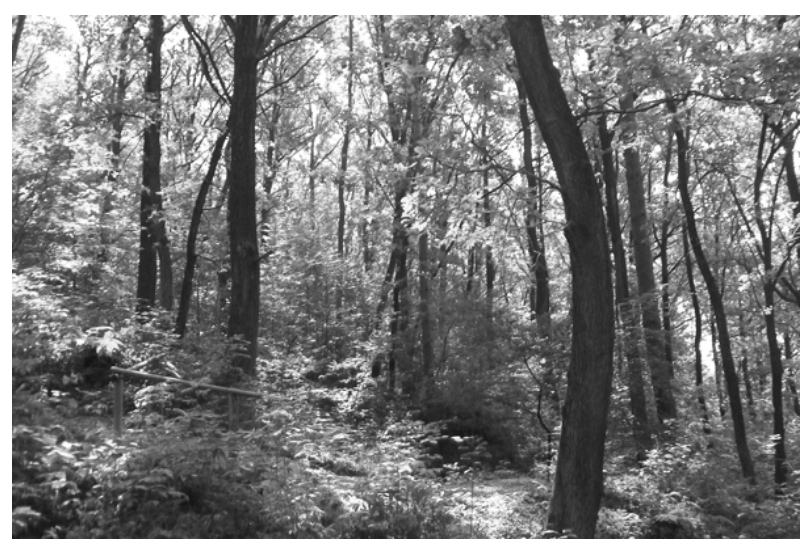

Fig. 4 Forest in nature reserve. 


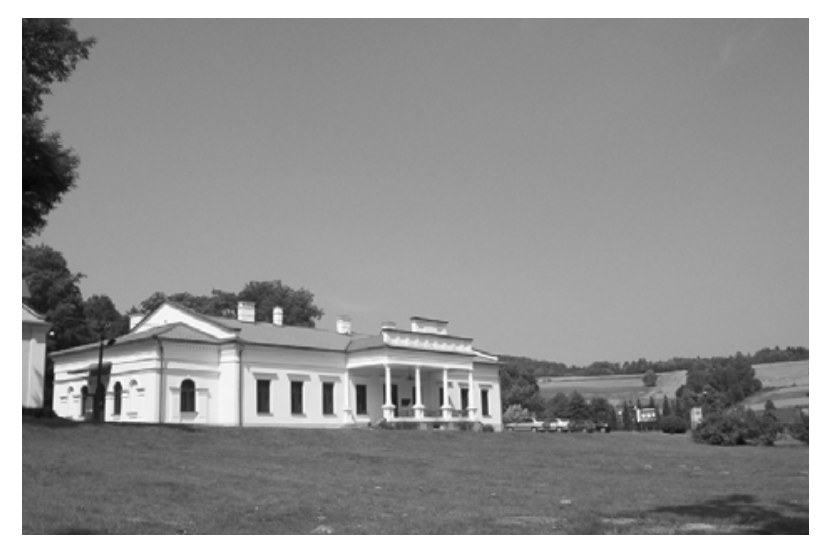

Fig. 5 Manor park in Kasna Dolna.

Among cultural elements, wooden architecture is dominant. Its representatives include historic wooden houses and churches. Moreover, there are also objects of cultural and natural significance: post-manor parks. The number of World War I cemeteries is significant. Currently, they hold a historic meaning and also serve as nature sanctuaries due to their diverse flora. A prominent place among objects of culture must be given to museums situated in the eastern part of the area under study. In Kąśna Dolina, there is a park and manor house of Ignacy Paderewski (Fig. 5). This venue is actively used, hosting concerts and other occasional events.

Three categories of study units have been identified in the area under study: very high, high, and moderate landscape values (Table 2). It should be stressed that areas of high landscape values dominate in Ciezkowice-Roznow regional park. Two areas have been classified as having very high landscape values, one as moderate value of flora and culture. There are no study units of low landscape values. Study units designated as $\mathrm{H}$ and $\mathrm{I}$ have been recognised as having highest landscape values. They are characterised by a high diversity of plant communities of natural and semi-natural kind, large forested areas, presence of natural monuments and natural 2,000 habitats, as well as diversified harmonious elements of culture. These units are in the eastern part of the area under study. Study units of high landscape value dominate in the area under study. These units are characterised by natural and semi-natural plant communities with a limited share of areas with synanthropic vegetation. These areas are a mixture of forested terrain (Fig. 6), rivers and smaller flows, and also agricultural lands. Large area is taken by forested terrain, as well as designated natural 2,000 settlements. Cultural landscape is also diversified. Elements such as historic wooden churches, World War I cemeteries and roadside shrines have been identified. This section of the study includes post-manor parks and sites of special importance. Identified types of nature preservation are: nature reserves, ecological cultivation areas and numerous natural monuments mostly represented by trees. Only one study unit (F) is characterised by moderate landscape values. This is where a valuable nature reserve, Skamieniałe Miasto located. Despite that the share of synanthropic vegetation, developement in the villages and small towns is significant.

Table 2 Results of landscape evaluation of municipalities in Ciezkowice-Roznow regional park in Poland.

\begin{tabular}{|c|c|c|c|c|c|c|c|c|c|}
\hline Assessment criteria/study units & A & B & C & $\mathbf{D}$ & $\mathbf{E}$ & $\mathbf{F}$ & G & $\mathbf{H}$ & I \\
\hline Size of forested area & 2 & 3 & 2 & 3 & 3 & 2 & 1 & 2 & 2 \\
\hline Diversification of plant communities & 3 & 3 & 3 & 3 & 3 & 3 & 2 & 3 & 3 \\
\hline Degree of natural flora & 0 & 0 & 2 & 0 & 0 & 0 & 0 & 1 & 2 \\
\hline $\begin{array}{l}\text { Presence of areas under protection (other than landscape } \\
\text { park as this is present in all communes under study) }\end{array}$ & 1 & 1 & 4 & 0 & 1 & 1 & 1 & 4 & 5 \\
\hline Presence of surface waters & 0 & 0 & 0 & 0 & 0 & 0 & 1 & 1 & 0 \\
\hline Diversification of cultural elements & 2 & 2 & 1 & 2 & 1 & 1 & 3 & 3 & 3 \\
\hline $\begin{array}{l}\text { Presence of harmonious and disharmonious cultural } \\
\text { elements within landscape }\end{array}$ & 3 & 3 & 3 & 3 & 3 & 3 & 3 & 3 & 3 \\
\hline Total points & 11 & 12 & 15 & 11 & 11 & 10 & 11 & 17 & 18 \\
\hline
\end{tabular}

* Areas of very high landscape value from 17 to 21 points, areas of high landscape value from 11 to 16 points, areas of moderate landscape value from 5 to 10 points and no areas of low value below 5 points — this area not exist on study areas. 


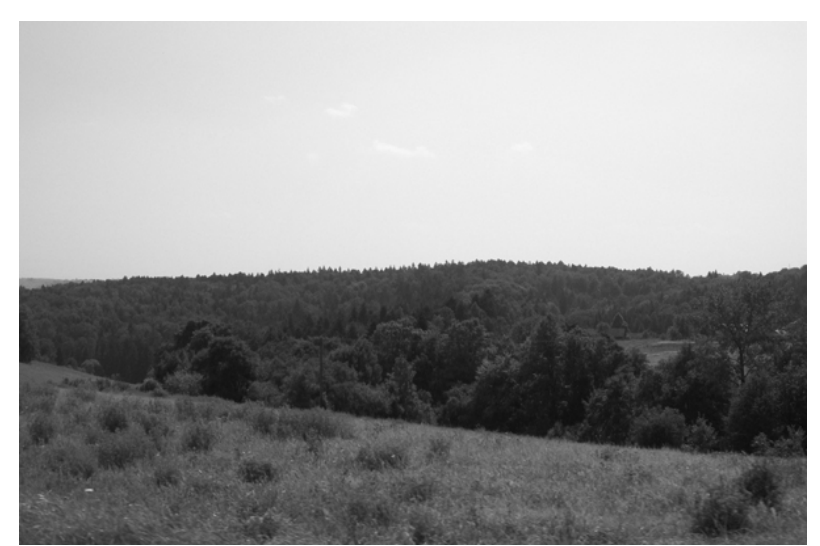

Fig. 6 View on mountain landscape.

Landscape has a number of functions: aesthetic, recreational, ecological and economical [2]. The same is true for the area under study. It should be stressed that finding a satisfactory solution combining the ecological, cultural, and economical aspects is not an easy task [6-8]. Landscape management for needs such as tourism, according to the principles of balanced development is commonly understood as one of the priorities of spatial policy of EU member states. European legislation highlights the need for reinforcing regional identity and preserving environmental and cultural diversity [9]. The quality of landscape is a backdrop to the development of communes especially in the aspects related to tourism.

\section{Conclusions}

None of the analysed study units has been graded with the maximum or minimum point score. Nevertheless, Ciezkowice-Roznow regional park is diversified both in the aspect of its flora and of its cultural environment, and their values. It holds a significant potential for the region especially regarding the growth of tourism and other activities in accordance with the principles of balanced development.

\section{Reference}

[1] Mazurski, K. 2012. The Concept of Landscape and Its Evaluation. Kraków: Proksenia.

[2] Myga-Piątek, U. 2007. "Culture Landscape as Value and Turistic Poroduct-Problem of Evaluation and Protection." Culture Landscape-Quality, Values, Protection, Problems of Landscape Ecology XVIII: 201-212.

[3] Żarska, B. 2012. Landscape Protection. Warsaw: SGGW.

[4] Kondracki, J. 2011. Regional Geography in Poland. Warsaw: PWN.

[5] Matuszkiewicz, W. 2012. Guidebook to Recognized Plant Comminities in Poland. Warsaw: PWN.

[6] Pawłowski, A. 2006. "Multidimensionality of Sustainable Development." Problems of Eco-development 1: 23-32.

[7] Pawłowski, A. 2008. "Sustainalbe Development-Idea, Phylosophy, Practice." Monographs of the Committee of Environmental Engineering 51: 499.

[8] Pawłowski, A. 2009. "Revolution in Sustainable Dvelopment." Problems of Eco-development 4 (1): 65-79.

[9] Myga-Piątek, U. 2011. "The Concept of Sustainable Development in Tourism." Problems of Eco-development 6: $145-154$. 